\title{
Direct radiation estimates from horizontal global irradiance values
}

\author{
V. Ruiz, F. Rosa, V. Fernández and M. Silva
}

AICIA, Escuela Superior de Ingenieros, Sevilla, Camino de los Descubrimiento s/n, 41092 Sevilla, Spain

\begin{abstract}
One of the main factors determining the economic feasibility of a solar thermal power plant is the availability of direct radiation at the plant site. During last years, two Central Receiver Power Plants (Solgas and Colon Solar) have been proposed in the South West of Spain (Huelva). For this area only global solar radiation data are available in a historical representative database. Based on an 11 years radiation database gathered at a nearby location, distance less than $100 \mathrm{~km}, 12$ correlations, (one per month), between $M_{t}$ and $M_{d}$ have been obtained. Solar global radiation data from the power plant site and generated correlations have allowed the "construction" of a Direct Radiation Design year that has been used both to design the solar plant heliostat field and receiver and to estimate annual energy produced by the solar plant.
\end{abstract}

\section{INTRODUCTION}

In a solar power plant, knowledge of direct irradiance distribution through a year is necessary to establish:

- The energy produced by the solar plant during a given period of time.

- The behavior of solar components, specially the receiver, during transient cloudy periods.

- The economic results of the solar system.

In hybrid concepts of solar plants as Solgas [1], solar and conventional thermal energy are integrated in a common system. The development of the appropriate energy interface, and the study of the operation strategy, require the knowledge of the solar direct radiation availability, and its temporal distribution.

When Solgas Project was proposed, no direct radiation values were available on site. Only a 5 years database with values of global mean irradiance on horizontal surface in 5 minutes time steps, was available. So that, it was necessary to apply a procedure to build up a solar direct radiation design year from available data, to optimize the solar plant design.

Several investigation groups agree pointing to the existence of a deep relation between diffuse/global irradiation ratio $\mathrm{K}_{\mathrm{d}}$, and global/extraterrestrial irradiation quotient, $\mathrm{K}_{\mathrm{t}}$. In the same way, a strong dependence from the diffuse/extraterrestrial irradiation quotient, $K_{d 0}$, can be found on the $K_{t}$ quotient. Some $K_{d}-K_{t}, K_{d 0}-K_{t}$ correlations to estimate values of diffuse irradiation, from global irradiation data to determine direct irradiation values, are available in literature. Depending of the irradiation integration step, can be grouped into:

- Hourly correlations: Orgills-Holland[2], Iqbal[3], Collares[4], Liu-Jordan[5], Frutos-Ruiz[6], etc.

- Daily correlations: Collares[4], Liu-Jordan[5], Muner-Hawas[7], Ruth-Chant[8], Frutos-Ruiz[6], etc.

- Monthly correlations: Frutos-Ruiz [6], Page[9], etc.

The use of one of these existing correlations to estimate direct solar irradiation from a 5 minutes mean global irradiance on horizontal surface database, was not considered adequate because: 
- They correlate ratios of irradiation (energy) instead of ratios of irradiance (power). The integration of 5 minutes mean global irradiance values into hourly, or longer irradiation values results in a loss of information.

- Most of them were calculated using measurements from locations faraway from the proposed, with different latitudes and climates.

So that, to generate a direct radiation design year for the solar plant site from the registered global irradiance values, 12, (one per month), mean irradiance in 5 minutes time steps correlations have been obtained from an 11 years radiation database of a nearby location, less than $100 \mathrm{~km}$ away.

\section{CORRELATIONS $M_{d}-M_{t}$ AND $M_{d 0}-M_{t}$}

Using irradiance instead of irradiation values, $M_{d}-M_{t}$ and $M_{d 0^{-}}-M_{t}$ correlations are obtained:

$$
M_{t}=\frac{I_{g}}{I_{0}} \quad M_{d}=\frac{I_{d}}{I_{g}} \quad M_{d 0}=\frac{I_{d}}{I_{0}}
$$

To elaborate the $M_{t}-M_{d}$ correlations, the following procedure was applied to the 11 years database of radiation measures in 5 seconds time interval, taken by the Group of Thermodynamics of the University of Seville:

- From the original database values, -time, global horizontal irradiance $\mathrm{I}_{\mathrm{gh}}$, diffuse horizontal irradiance $I_{d h}$, and direct irradiance $I_{D}$, mean irradiance values in 5 minutes time intervals were calculated.

- From theory, extraterrestrial horizontal irradiance $\mathrm{I}_{0 \mathrm{~h}}$ at the middle time of each mean irradiance value was calculated.

- $M_{t}, M_{d}$ and $M_{d 0}$ were calculated and checked to avoid inconsistencies.

- The filtered database sample was classified into 12 monthly subsamples.

- For each month, the relation between $M_{t}$ and $M_{d}$ was analyzed dividing the $[0,1] M_{t}$ interval into 40 subintervals. Distribution of $M_{d}$ in each subinterval is not a normal distribution, and is strongly dependent of the number of available data inside the interval. In fact, sometimes it can be adjusted to a modal distribution, in other cases can be adjusted to a bimodal distribution. Due to the former reasons, and taking into account that median values are very close to modal ones, the median value of $M_{d}$ and the medium value of $\mathrm{M}_{\mathrm{t}}$ for each subinterval were chosen as their representatives values.

- $12 \mathrm{M}_{\mathrm{d}}-\mathrm{M}_{\mathrm{t}}$ correlations, one per month, were calculated and used as specified in next section.

Mt values over 0.8-0.85 make no sense from a physical point of view. Median $M_{d}$ values for intervals higher than these $M_{t}$ limits have not been calculated.

Figure 1 to Figure 12 present the analyzed sample, and representative $M_{d}-M_{t}$ point for each monthly subsample interval. 


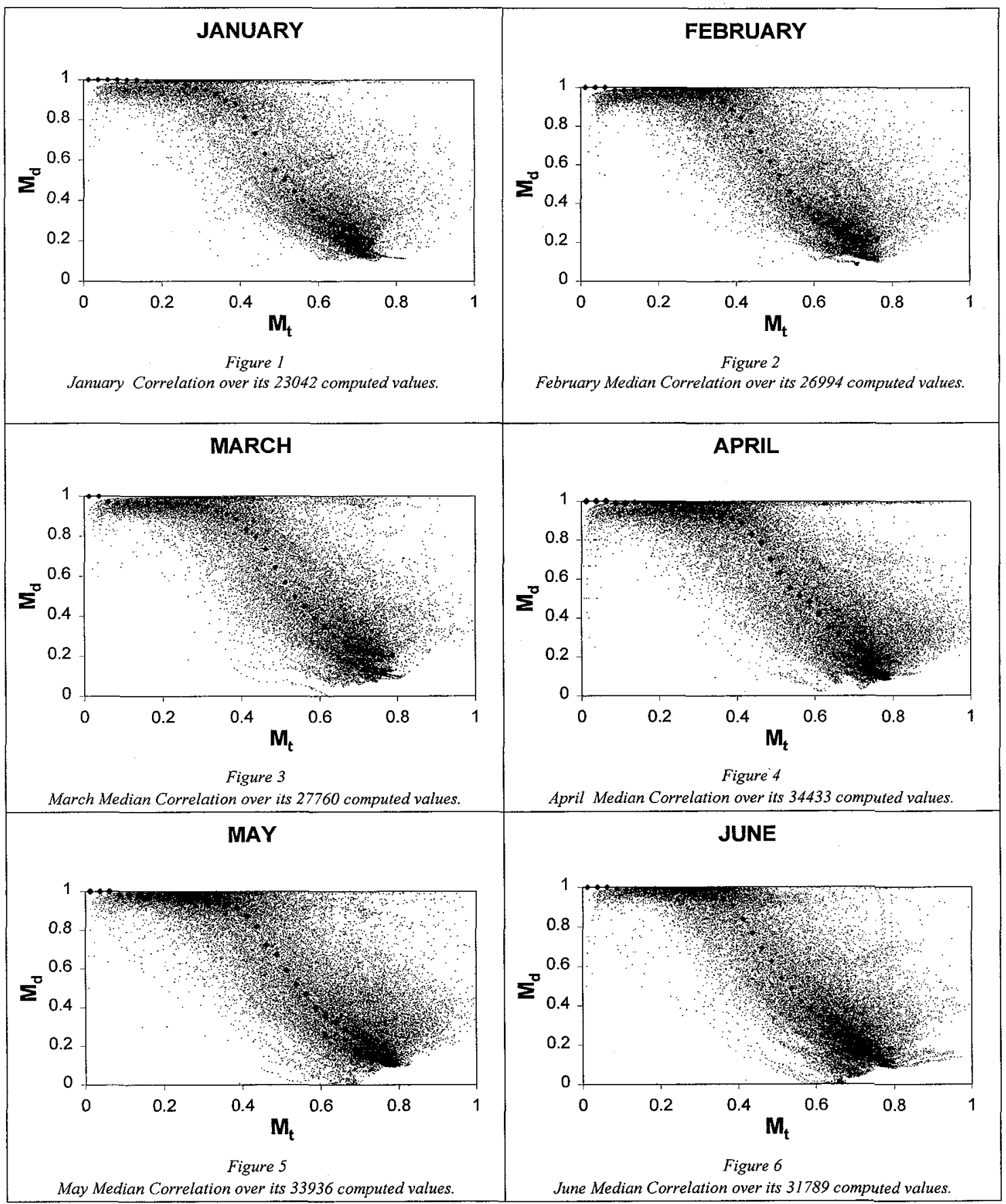




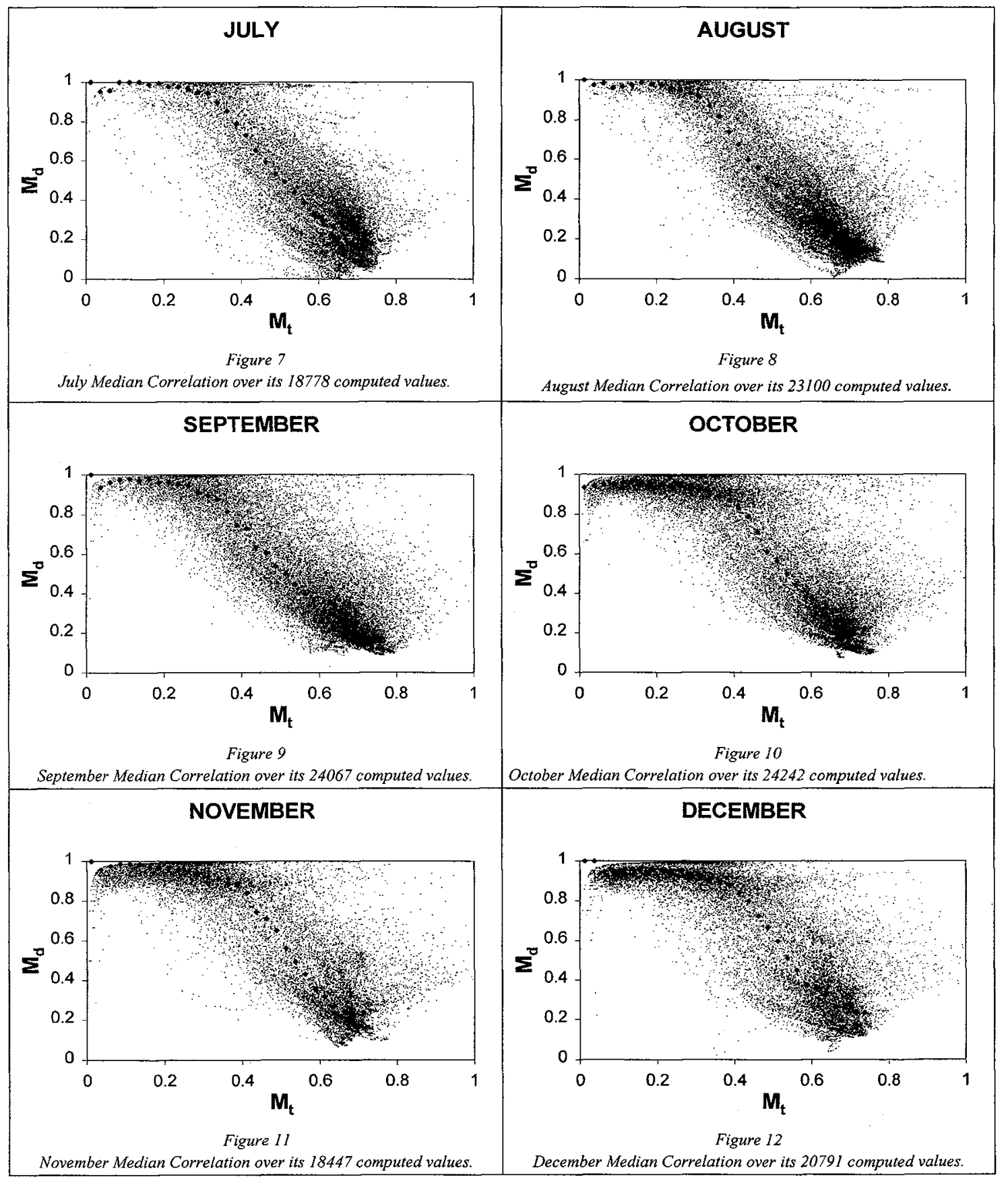




\section{ESTIMATION OF DIRECT IRRADIANCE VALUES FROM HORIZONTAL GLOBAL IRRADIANCE MEASUREMENTS}

To generate the mean direct irradiance design year from the 5 minutes database of global mean irradiance, the following procedure was applied:

- Calculation of solar time.

- Determination of extraterrestrial solar irradiance for the Julian day and solar time.

- Calculation of $\mathrm{M}_{\mathrm{t}}$.

- Calculation of $\mathrm{M}_{d}$ from correlations presented in the former section.

- Calculation of diffuse irradiance on horizontal surface, based on $\mathrm{M}_{\mathrm{d}}$ and global irradiance.

Finally, following expressions were used to calculate Direct Irradiance:

$$
\begin{gathered}
I_{D, h}=I_{g, h}-I_{d, h} \\
I_{D}=\frac{I_{D, h}}{\operatorname{sen} \alpha}
\end{gathered}
$$

with,

$\mathrm{I}_{\mathrm{D}, \mathrm{h}}=$ Direct irradiance on horizontal surface.

$\mathrm{I}_{\mathrm{D}} \quad=$ Direct irradiance

$\mathrm{I}_{\mathrm{g}, \mathrm{h}}=$ Global irradiance on horizontal surface

$\mathrm{I}_{\mathrm{d}, \mathrm{h}}=$ Diffuse irradiance on horizontal surface.

$\alpha \quad=$ Elevation angle of the Sun.

\section{RESULTS}

The quality of direct irradiance estimations from global irradiance has been checked with the direct and global irradiance values measured at the meteo station installed at the plant site. Direct irradiance was calculated from global irradiance following the procedure described above. Both measured direct irradiance and calculated direct irradiance were then compared. Figure 13 presents daily evolution of calculated and measured direct irradiance, showing the good agreement existing between measured and estimated values of direct radiation.

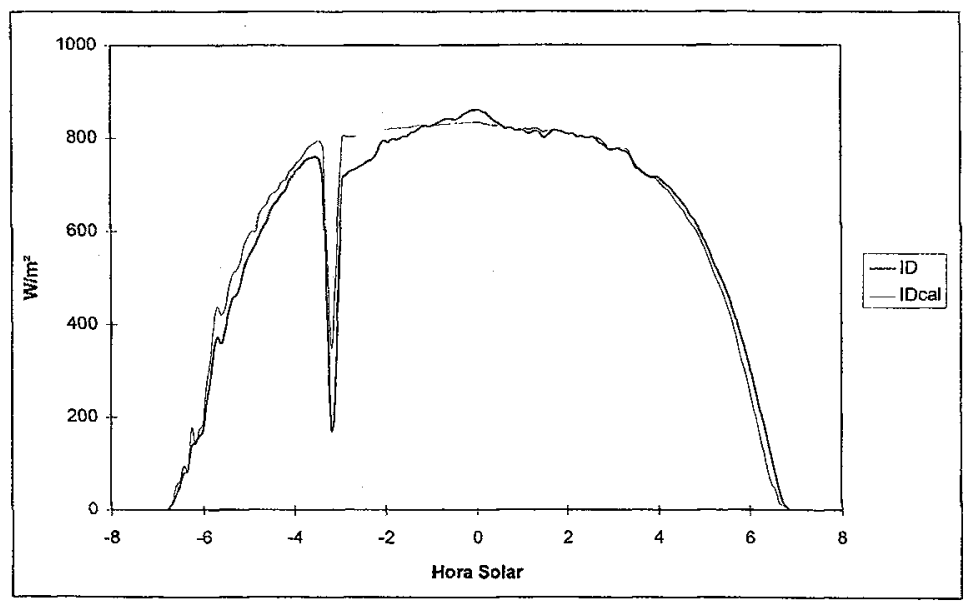

Figure 13.- Measured and estimated direct irradiance daily evolution. 
Continuos operation of the Data Acquisition System has permitted to get data of direct and global irradiance values during a whole year.

\section{CONCLUSIONS}

Comparison of calculated and estimated values of direct irradiance leads to the following conclusions:

- For very clear days, direct irradiance values are approximately $10 \%$ less than measured ones.

- For clear days, method estimates correctly incident direct irradiance on site.

- Precision is not dependant of the period of year.

- For annual estimations, calculated direct irradiation results $2 \%$ lower than measured direct irradiation.

\section{References}

[1] M. Blanco and V. Ruiz. The Solgas Proyect. Proceeding of the European Conference and Contractors Meeting. Venice, Italy. November, 1995.

[2] J.F. Orgill and K.G.T. Holland. Correlation equation for hourly diffuse radiation on a horizontal surface. Solar Energy, 19, 357-359. 1977.

[3] M. Iqbal. Prediction of hourly diffuse solar radiation from measured hourly global radiation on a horizontal surface. Solar Energy, 23 (5), 491-503. 1980.

[4] M. Collares-Pereira and A. Rabl. The average distribution of solar radiation correlations between diffuse and hemispherical and between daily and hourly insolation values. Solar Energy, 22 (2), 155-164, (1979).

[5] B. Liu and R.C. Jordan. The interrelationship and characteristic distribution of direct, diffuse and total solar radiation. Solar Energy, 4, 1, 19. 1960.

[6] Fabian Frutos. Tesis Doctoral. Universidad de Sevilla. 1987.

[7] T. Liu and N.M. Hawas. Correlation between daily diffuse and global radiation for India. Energy Covers, Mgmt, 24 (2), 151-154. 1984.

[8] D.W. Ruth and R.E. Chant. The relationship of diffuse radiation to total radiation in Canada. Solar Energy, 18, 153-154. 1976.

[9] J.K. Page. The estimation of monthly mean values of daily total shortwave radiation on vertical and inclined surfaces from sunshine records for latitudes 40N-40S. Proc. U.N. Conf. New Sources Energy. Paper 598, 4, 378-390. 1961. 